NASA Technical Memorandum 103206

AIAA-90-2503

\title{
Low Thrust Rocket Test Facility
}

\section{Lynn A. Arrington}

Sverdrup Technology, Inc.

Lewis Research Center

Brook Park, Ohio

and

Steven J. Schneider

National Aeronautics and Space Administration

Lewis Research Cenier

Cleveland, Ohio

Prepared for the

26th Joint Propulsion Conference

cosponsored by the AIAA, SAE, ASME, and ASEE

Orlando, Florida, July 16-18, 1990

\section{NMS}

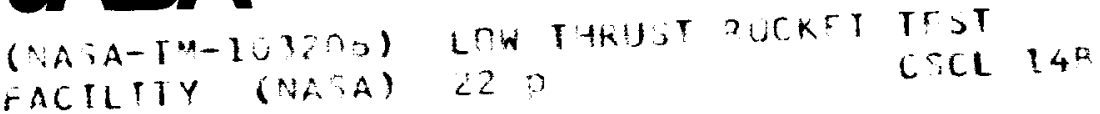




\section{LOW THRUST ROCKET TEST FACILITY}

\author{
Lynn A. Arrington \\ Sverdrup Technology. Inc., LeRC Group \\ Brook Park, Ohio 44142
}

\author{
Steven J. Schneider \\ NASA Lewis Research Center \\ Cleveland, Ohio 44135
}

\section{Abstract}

A low thrust whemical rocket test facility has recently become operational at the NASA Lewis Research center. The new facility is used to conduct both long duration and performance tests at altitude over a thruster's operating envelope using hydrogen and oxygen gas for propellants. The facility provides experimental support for a broad range of objectives, including fundamental modeling of fluids and combustion phenomena, the evaluation of thruster components, and life testing of full rocket designs. This paper describes the major mechanical and electrical systems along with aspects of the various optical diagnostics available in the test cell. The electrical and mechanical systems are designed for low down time between tests and low staffing requirements for test operations. Initial results are also presented which illustrate the various capabilities of the cell.

\section{Introduction}

A sustained development activity in low thrust chemical rockets has been initiated at the NASA Lewis Research center with the operation of a new low thrust rocket test facility. Hot fire check out of this hydrogen-oxygen thruster test facility, which began in Felruary of 1989, is complete. The test cell and adjacent control room are built as an autonomous facility with the objective of a fast turn around time for hardware and software and a mirimal staffing requirement for operation. The facility is desigred to test the 22-220 N (5-50 1bf) thruster class with a nozzle to throat area ratio of $30: 1$ at altitude conditions of $36 . \epsilon \mathrm{km}(120,000$ feet $)$.

The test cell is used to conduct a variety of experiments. performance characteristics are determined for a thruster over its operating envelope of mixture ratios and chamber pressures. Life tests are conducted under steady state and pulsed conditions. High temperature materials are evaluated for their chamber life: as a function of the operating conditions. Different ignition concepts are also tested and evaluated. optical access is available in the test tank for laser, spectroscopic, ancl thermographic measurements. Test results are used to support the development of analytical design and performance prediction tools for rockets in general, and to evaluate and optinize the life and performance of small 
thrusters. Rocket design and analysis tools can be developed at a low verification cost using the low thrust facility. These tools will have applications for high thrust class rockets as well. The following is a description of the physical layout of the facility with each of its mechanical, electrical and optical diagnostic systems. Examples of other test facilities ${ }_{8}$ are available in the references at the end of this text.

\section{Facility Description}

Overview:

The general layout of the test facility is shown in Figure 1. The facility is divided into the service area, control room, and test cell. The service area is used to prepare experimental hardware and contains tools and a work area. The control room holds all the data acquisition equipment along with monitoring and controlling equipment for the test rig and the facility. The facility control and data acquisition equipment are shown in Figure 2. In the test cell, the major components of the test rig are the vacuum tank, thrust stand, diffuser, water cooled pipe and spray cart as seen in Figures 3 and 4. A two-stage ejector and a pair of mufflers are located outside of the cell area downstream of the spray cart.

The test cell contains separate fuel, oxidizer, water, nitrogen, and air systems. Figure 5 is a block diagram of the interconnections of each of these mechanical systems. The fuel and oxidizer systems supply gaseous hydrogen and oxygen for propellants. Water cools the exhaust components and combustion gases. Nitrogen gas is used to purge both fuel and oxidizer lines and is used for pneumatic valve control and thrust stand calibration. Air acts as the motive gas for a two-stage ejector system that creates the vacuum in the test tank. The facility has three interconnected electrical systems: the facility programmable controller, safety monitor systems and research data acquisition systems. These systems interact with the facility hardware and are interfaced with a personal computer. These are shown in the instrumentation and control block diagram in Figure 6 . The facility programmable controller is programmed with the sequencing of the facility components required to conduct a test and also includes sequencing of the valves and igniter on the research hardware. The safety monitoring systems include an abort monitor, an annunciator, and hydrogen gas detectors. The data acquisition system monitors the research hardware, redlines out-of-tolerance conditions, and sends messages to the facility programmable controller to terminate the test as required. The data acquisition system is programmable through the personal computer. 
In addition, ground support equipment is available within the cell for nonjunvasive diagnostics. These include Rayleigh scattering, Ramar scattering, and laser-induced fluorescence measurements of various combustion gas parameters in the combustion chamberr, nozzle, and plume flow field. Thermographic and pyrometric djagnostics are also available for determining material temperatures.

Test stand:

The stainless steel vacuum tank is 0.91 meters (three feet) in diameter and 3.82 meters (six feet) long. One end cap is stationary and contains all electrical, instrumentation, and supply feed-throlghs as shown in Figure 7. The thruster mounts in a thrust stanc. which also bolts to the stationary end of the test tank. The cylindrical portion of the tank is supported on wheels, which allows the tank to be rolled back $1.22 \mathrm{~m}$ (four feet) for access to the thruster. In the walls of the test tank are four fused silica viewports. Three are located in a plane perpendicular to the axis of the nozzle and the other at a 60 degree angle with the nozzle axis. These viewports provide optical access fcr laser, spectroscopic, and thermographic equipment as shown in Figure 8.

The thrust stand holds the axis of the thruster within the test tank in a hcrizontal plane by using flexible supports. The thrust stand can be modified to accommodate different size thrusters and contains both measurement and calibration loadcells for thrust measurement. Prior to each test day, a series of regulated pressures are applied to a piston and housing assembly which transmits the same force to each load cell. Then, using the known calibration loadcell reading, a calibration curve can be determined for the measurement loadcell.

A diffuser, with an inside diameter of $10.2 \mathrm{~cm}$ (four inches), is located downstream of the thruster nozzle with its axis parallel to the thruster to catch the exhaust. The diffusion of the supersonic exhaust to subsonic conditions provides an additional pumping effect to maintain the tank vacuum during firing. Water channels within the walls of the diffuser keep it cool during combustion. The relative distance between the diffuser and the end of the nozzle can be manually adjusted by means of a bellows joint downstream of the spray cart. This bellows is also used to accommodate different thruster sizes. The other end of the diffuser is attached to a water cooled pipe. The tank rolls back along this pipe for thruster access and forms a seal on this pipe when the tank is closed for testing. Exhaust travels through the water cooled pipe and into a spray cart.

The spray cart has a continuous water spray which flows at approximately $0.12 \mathrm{l} / \mathrm{sec}(1.9 \mathrm{gpm})$. During combustion, an 
automatic temperature controller responds by increasing the water spray to provide additional cooling. The cooled exhaust exits the spray cart into a two-stage ejector. By running a lower flow rate during non-firing periods, the amount of water pulled into the ejectors is reduced.

Propellant systems:

Fuel and oxidizer are şupplied for the test facility by two $16.5 \mathrm{MPa}(2400 \mathrm{psi}), 2000 \mathrm{~m}^{3}(70,000 \mathrm{scf})$ hydrogen and oxygen trailers which allow for a total impulse of $1.1 \times 10^{6} \mathrm{Nsec}\left(2.5 \times 10^{5}\right.$ $1 \mathrm{~b}-\mathrm{sec})$ at the maximum design flow rates. Each trailer is parked at a separate trailer station and has a globe valve to isolate the trailer from the supply piping and a filter that removes particles down to 10 microns from the gases. The trailer stations are separated from the proximity of the test cell and each other by distance, concrete walls or earthen mounds. As the hydrogen and oxygen systems are nearly identical, a simplified piping schematic for the two systems is shown in Figure 9 with the differences indicated. oxygen is supplied to the test cell by $71.6 \mathrm{~m}(235$ feet) of $1.91 \mathrm{~cm}(3 / 4$ inch) stainless steel tubing at ambient temperatures. Hydrogen is supplied to the cell by $48.8 \mathrm{~m}$ (160 feet) of $2.54 \mathrm{~cm}$ ( 1 inch) stainless steel welded pipe, also at ambient temperatures. Both systems separate external piping from interior cell piping by globe valves mounted on the opposite test cell walls. Plumbing internal to the test cell is similar for the two systems. A remotely operated dome regulator is located downstream of each globe valve, but just outside of the building, to control the Iine pressures within the cell to a maximum pressure of $5.2 \mathrm{MPa}$ (750 psig). All supply piping within the cell reduces to $1.27 \mathrm{~cm}$ ( $1 / 2$ inch) stainless steel tubing. The regulator sets the upstream pressure for the calibrated sonic venturis or orifices to control the fuel and oxidizer flow rates to the thruster. For safety a globe valve, which acts as a fire protection valve, is located between each flow venturi and regulator to isolate the facility from the test hardware when not combusting. For additional safety, both systems are isolated from each other as much as is feasible until the fuel and oxidizer enter the thruster. The status of pressures and temperatures within these two supply lines is continuously monitored on panel meters located in the control room. Maximum flow rates for the hydrogen and oxygen lines are $0.010 \mathrm{~kg} / \mathrm{sec}(0.022 \mathrm{lbm} / \mathrm{sec})$ and 0.0363 $\mathrm{kg} / \mathrm{sec}(0.08 \mathrm{lbm} / \mathrm{sec})$, respectively.

Support Systems:

The two-stage ejector, which provides the suction for the tank vacuum, is shown in Figure 10. Air at $862 \mathrm{kPa}$ (125 psig) 
and $4.5 \mathrm{~kg} / \mathrm{sec}(10 \mathrm{lbm} / \mathrm{sec})$ is used as the motive gas. The air supply system is maintained and operated independently of this facility and will not be described in this paper. Air flow through the ejector is manually controlled by two remote butterfly valves. The first, smaller, stage normally operates at a pressure of $655 \mathrm{kPa}$ (95 psig) and the second stage normally operates at a pressure of $724 \mathrm{kPa}$ (105 psig). This pulls a vacuum of between 1.4 and $2.1 \mathrm{kPa}(0.2$ and $0.3 \mathrm{psia})$ and takes less than 5 minutes to establish. During a test the pressure will be slightly lower due to the pumping effect of the diffuser. once the exhaust exits the ejector, it enters two parallel

mufflers which reduce noise. The mufflers vent to atmosphere.

The water comes from the city water supply which maintains a pressure of about $310-345 \mathrm{kPa}$ (45-50 psig). A pump increases the water flow through the diffuser and the spray cart to about 4.7 $1 / \mathrm{sec}$ and $0.12 \mathrm{l} / \mathrm{sec}(75 \mathrm{gpm}$ and $1.9 \mathrm{gpm})$, respectively. The water cooled pipe usually flows at $1.9-2.21 / \mathrm{sec}(30-35 \mathrm{gpm})$. Water from the diffuser and water cooled pipe dump directly into a floor drain. Water from the spray cart collects in a tank beneath the spray cart and empties automatically into another tank when a level switch indicates the spray cart tank is full. The second tank is emptied while the first is filling. In this way the vacuum can be maintained while disposing of the excess water.

Gaseous nitrogen is used to control all the remotely actuated valves on the hydrogen and oxygen systems. Nitrogen is also used to purge the hydrogen and oxygen supply lines, the test hardware, electrical boxes, and the vacuum tank. Nitrogen can be introduced at a pressure of $1.90 \mathrm{MPa}(275 \mathrm{psig})$ at two places in each of the supply lines; one upstream of the regulator and the other downstream of the fire valves. Check valves at each location prevent hydrogen or oxygen from being introduced back into the nitrogen system. For venting down and purging, the hydrogen and oxygen systems each have two vent locations. One is at the trailer station and the other connects just outside of the test tank. Nitrogen is supplied by a $3100 \mathrm{~m}^{3}(110,000 \mathrm{scf})$ stationary tank at $16.5 \mathrm{MPa}(2400 \mathrm{psi})$ maximum pressure, which is shared by other facilities located in the same general area. The nitrogen is supplied to the test cell by $1.91 \mathrm{~cm}(3 / 4$ inch) stainless steel tubing at a maximum flow rate of $0.54 \mathrm{~kg} / \mathrm{sec}(1.2$ $1 \mathrm{bm} / \mathrm{sec}$ ).

Facility control:

With the exceptions of the air ejector valves and several other facility valves which are controlled by electro-pneumatic controllers and operate by push button, respectively, the remote facility valves are controlled by a programmable controller and panel mounted push buttons. The controller, using ladder logic, 
monitors 128 inputs and 128 outputs. These inputs and outputs are connected to $24 \mathrm{VDC}$, except for those interacting with the data acquisition system which are 5 VDC relays. By checking continuously for the programmed operating conditions, it sequences and times valves for test runs, purges, water removal, normal shutdowns, and emergency shutdowns. Through the analog outputs, the controller operates mechanical relays to provide power to both facility and hardware valves. An emergency shutdown sets all valves to their safe positions and bleeds hydrogen and oxygen from the interior cell piping. A normal shutdown closes only the thruster and fire valves. This allows most of the test cell operations to be automatic, though final shutdown, start-up, and regulator settings are operator controlled. The controller interfaces with the data acquisition system which determines the length and type of test to be run. However, the programmable controller does control the thruster valves and igniter sequencing to start or stop a test run. A typical timing sequence for a thruster test is shown in Figure 11. The valves are programmed with lead or lag in $10 \mathrm{msec}$ increments as required by different thrusters.

\section{Safety systems:}

As mentioned, supply lines pressures, temperatures, and flow rates are continuously monitored in the test cell control room and displayed on panel meters. Some of the panel meters have low and/or high pressure limits which, when exceeded, causes the meters to send inputs to the programmable controlier, preventing the opening or closing of certain interlocking valves during startup or shutdown procedures. In this way, by following a checklist, a series of permissives are satisfied to start up a test. For instance, to bring oxygen into the cell piping, pressure must first be bled up slowly through a flow restricting orifice, bypass line, and valve before the main building valve can be opened. This prevents forcing high pressure oxygen into empty tubing. Another example is that the hydrogen and oxygen supplies must be vented prior to opening the purge valves.

The abort monitor checks the health of the facility. It continuously monitors critical facility and research pressures, temperatures and flow rates for high or low limits. If a high or low limit is exceeded, the abort monitor sends a signal to the programmable controller and to an alarm display panel called the annunciator panel. In response to that signal, the programmable controller takes the appropriate action. An abort monitor alarm must be satisfied prior to a test run, but it can also shutdown a run if an alarm occurs. For example, a normal shutdown is initiated if the flow rate in the water cooled pipe drops below $1.9 \mathrm{l} / \mathrm{sec}$ (30 gpm). Also, the abort monitor verifies ignition in a run sequence by monitoring the rise in chamber pressure. The 
annunciator is a lighted panel which displays the type of alarm that has occurred. There are a total of 18 different alarms. Alarms can occur for each of the mechanical systems, water, hydrogen, oxygen, air, and nitrogen. There can also be alarms for the research hardware, test cell vent fan, or programmable controller failure.

To check for a hydrogen leak, four hydrogen detectors are located within the test cell. One is located where hydrogen enters the building, one outside the tank bulkhead, another inside the test tank, and the last near the vent fan. The three outside of the test tank detect hydrogen at $20 \%$ by volume of the lower explosive limit which is $4 \%$ hydrogen by volume. This causes both audible and visual alarms. At $40 \%$ of the lower explosive limit, both audible and visual alarms occur plus an emergency shutdown. The vent fan keeps air circulating within the cell and prevents hydrogen pockets from forming in case of a leak. Within the tank itself, unburned hydrogen results when the fuel valve leads or lags the oxidizer valve in opening or closing. This caused many shutdown alarms so the limits are set higher at $60 \%$ and $80 \%$ of the lower explosive limit. Another safety feature for fire protection is the carbon dioxide system. A manually operated push-button shuts down the vent fan and floods the entire cell with carbon dioxide.

While hydrogen and oxygen are within the cell, the test cell and surrounding area are restricted to all personnel. Cameras monitor the exclusion area outside of the cell and the area within the cell. Also, there is a camera which focuses on the thruster through one of the viewports. For safety, two people must be present in the control room and an extensive checklist followed to operate the test cell.

Data Acquisition:

The research data acquisition systems record and display both digital and analog data. The digital data acquisition system serves two functions, the first of which is as a stand alone system monitoring ali the research data. This includes thruster thermocouples, pressure transducers, and the thrust measuring load cell. currently the system can record readings from 24 pressure transducer and 40 thermocouples. These readings are continuously monitored for out-of-tolerance conditions which can produce a visual alarm or a normal run shutdown. Data are temporarily stored at a predetermined sampling rate during a test run. Hydrogen ard oxygen mass flow rates, mixture ratio, vacuum thrust, specific impulse, thrust coefficient, and characteristic exhaust velocity are also calculated in real time and stored. When a run is completed, a personal computer is used to retrieve and store data permanently on floppy disks. Data can then be reduced further and displayed in graphical format. During a run, 
the research data are displayed in graphical and tabular form on two video monitors. The data acquisition system can be programmed for different instrumentation requirements depending on the particular thruster. For rapid turn around in testing, each instrumentation configuration is stored on a personal computer and uploaded to the data acquisition system prior to running.

The second function of the data acquisition system is to interact with the programmable controller to control the test run parameters. A series of menu screens on the personnel computer allow the operator to select the type, duration, data sampling rate and alarm limits for a run. These are communicated to the data acquisition system prior to the run. Typical recovery and set up time is from four to ten minutes depending on the amount of data which needs to be downloaded at the end of the previous run. The data acquisition system also indicates to the controller when to start and stop tests through a series of TTL logic bits. Different types of tests would be steady state, cyclic, or impulse bit. Steady state tests can last from a few seconds to a hour. A cyclic test can run from a 2 sec on-2 sec off duty cycle for 3000 cycles to a $1000 \mathrm{sec}$ on-100 sec off cycle for 100 cycles. An impulse bit test has a minimum duty cycle of $400 \mathrm{~ms}$ on $-400 \mathrm{~ms}$ off for 250 cycles to a maximum duty cycle of 1 sec on-1 sec off for 90 cycles. An impulse bit test varies from a cyclic test in that chamber pressure need not be satisfied to continue the run. Therefore, the actual run duration is limited to when the unburned hydrogen in the tank reaches the detector limits. Though the data acquisition system monitors impulse bit tests, it does not record the full range of data during the runs. The system is too slow to record the transient nature of an impulse bit test.

Two other pieces of data acquisition equipment are used in the control room. One is a strip chart or brush recorder which records five transducer readings and igniter, thruster fuel and oxidizer valve markers. This recorder is useful for doing immediate postrun analysis of transient data and in determining causes for ignition failure. The other is an FM tape recorder which has 13 data channels and a time code channel. It serves as a back up system in case of a data acquisition system failure and also records transient data for impulse bit testing.

Optical Diagnostics:

Optical access to the test tank permits development of noninvasive diagnostics such as Rayleigh and Raman scattering spectroscopy and laser-induced fluorescence. The Rayleigh technique uses an argon ion laser. The laser beam is scattered off of combustion products and is collected from a point $2.22 \mathrm{~cm}$ $(7 / 8$ in) downstream of the exit plane of the nozzle along the 
centerline. Ideally measurements can be made anywhere within the plume. From the spectrum collected, local number density, temperature, and velocity are determined for the combustion products. The Raman scattering apparatus, which is under construction, will be used to measure the temperature and major species concentration anywhere within the flow. A flashlamp pumped dye laser sends a beam along optical fibers into the test tank. Initially measurements will be made near the exit of a low area ratio nozzle where the pressure is near one atmosphere. Later, sapphire windows will allow measurements within the combustion chamber itself. The laser-induced fluorescence apparatus, which is also under development, will be used to measure minor species concentrations anywhere in the flow. A Nd:YAG-pumped dye laser is used for excitation. Initially, two-dimensional images of the of fluorescence signal will be used for qualitative flow analysis. Accurate quantitative data on the oH number density will be acquired through simultaneous measurements of Raman and $\mathrm{OH}$ fluorescence emissions at a point. The experimentally obtained Rayleigh, Raman, and laser-induced fluorescence data will be compared with theoretical predictions of species number densities, temperature, and velocity for analytical model development.

An infrared camera with a video tape recorder and video monitors gives qualitative thermographic data for a run. It helps locate thruster hot spots and is the only visual way of confirming thruster ignition as hydrogen-oxygen combustion does not emit visible radiation. A two-color pyrometer is also available for measurements of high temperatures.

\section{Results}

Facility Checkout:

A previously tested thruster of known performance characteristics was used for facility checkout. The particular thruster was a $110 \mathrm{~N}(25 \mathrm{lbf})$ thrust class with $40 \%$ boundary layer cooling and an area ratio of $30: 1$. Tests were conducted over a range of oxygen to hydrogen mixture ratios from 3 to 8.5 and a range of chamber pressures from 345 to $690 \mathrm{kPa}$ (50 to 100 psia) to produce a thrust between 55.5 and $110 \mathrm{~N}(12.5$ and 25 lbf). Steady state tests were run up to 10 minutes with no overheating of the test rig or test hardware. Also, cyclic tests were successfully run from $2 \mathrm{sec}$ on-2 sec off for 50 cycles to $100 \mathrm{sec}$ on-50 sec off for 10 cycles. The purpose of these tests was to verify all operations of the automatic control and physical systems. These checkout tests revealed minor problems with the automatic thruster valve sequencing and with the water drainage which were corrected. All other systems were run through many scenarios to verify correct operation and adequate 
capability under both normal and emergency circumstances. The air ejector system maintained the pressure at less than $1.3 \mathrm{kpa}$ ( $0.19 \mathrm{psia})$ for the entire range of mixture ratios tested as shown in Figure 12. The appearance that the steady state level of the tank pressure was related to the mixture ratio was just an artifice of the tests shown. The steady state tank pressure was predominately affected by the tank pressure just prior to firing. Prefiring pressures, though difficult to read from the graph, were higher for the higher mixture ratios. These higher pressures were the result of difficulties in maintaining the same vacuum pressure throughout a test day due to the effects of water collection in the ejectors and from variations in the ejector motive air supply. The specific impulse obtained from these checkout tests compared favorably with that obtained previously using the same thrustgr at the NASA Marshall space Flight center as seen in Figure 13 .

Subsequent Testing:

With the completion of check out, other research projects were initiated. In cooperative programs with industry, a number of thruster components were tested, including a unique high temperature chamber material and an advanced igniter. In addition, performance studies were undertaken on hardware developed under the space station Freedom program. The hardware operated at stoichiometric mixture ratio, was regenatively cooled, and employed fuel film cooling of the chamber walls. The previously untested thruster was ignited and studied for mixture ratios from 3 to 8 , thrust levels of 75-110\% of nominal, and fuel film cooling levels of 55-65\%.

Preliminary measurements in the plume of a $110 \mathrm{~N}$ (25 1bf) thruster were made with the Rayleigh scattering diagnostics. 1 Data were obtained for a mixture ratio of $7.8: 1$ and a chamber pressure of $690 \mathrm{kPa}$ (100 psia). The exhaust gases were assumed to predominately of water vapor. At the nozzle centerline and approximately $2.22 \mathrm{~cm}(7 / 8 \mathrm{inch})$ downstream of the exit plane, velocity and temperature measurements of $3831 \mathrm{~m} / \mathrm{s}(12570 \mathrm{ft} / \mathrm{sec})$ and $1125 \mathrm{~K}(2025 \mathrm{R})$, respectively, were made. These results compare favorably with the results of a one-dimensional kinetic expansion which predicts a velocity of $3720 \mathrm{~m} / \mathrm{s}(12210 \mathrm{ft} / \mathrm{sec})$ and a temperature of $1257 \mathrm{~K}(2263 \mathrm{R})$. I2 As of this writing, the Raman and laser-induced fluorescence equipment was being installed in a separate climate controlled room.

Operational Requirements:

With the completion of check out and some subsequent testing certain items were determined for the facility. For instance, 
replacing the first thruster with the second took almost a week and a half. With experience the turn around time was decreased to one or two days. If the hardware was previously used, turn around could be completed in an afternoon. On a typical test day, between twenty and thirty steady state tests were completed over the full range of operating conditions. The testing to date has revealed some of the critical factors in thruster

installation. The first was the proper sequencing of the fuel and oxidizer thruster valves for simultaneous injection into the rocket chamber. This prevents unburned a hydrogen from setting off the hydrogen detector alarm within the tank. The second factor was the clitical nature of the relative positions and alignment of the diffuser and thruster exit plane. If they were too close, too fir apart, or the axes not well aligned, the vacuum could not be maintained. Improper alignment of the thruster and dif:user axes caused pressure to build up in the tank as the exhaust impinged on the face of the diffuser.

on a typical test day, four people were required to set up and operate the tiest cell. At the start of a test day, one instrumentation technician set up and calibrated the control room instrumentation such as pressure transducers, the FM tape recorder, and stuip chart recorder. That person was further required only if instrumentation irregularities were encountered. Another technician activated the mechanical systems by opening and closing the appropriate manual valves and adjusting regulator pressures during set up procedures. The mechanical technician did essentially the reverse procedure during shutdown. During operations only two people were required; one to operate facility controls and another to operate the computer and record the run log. The laser systems operated independently of the cell and were not included in the staffing requirements.

\section{Conclusions}

A new low thrust chemical rocket test facility is in operation at the NASA Lewis Research Center. The facility supports both research and development activities in low thrust gaseous hydrogen-oxygen chemical propulsion. The facility is capable of maintaining altitudes up to $36.6 \mathrm{~km}(120,000$ feet) and can handle thrust levels up to $220 \mathrm{~N}$ (50 lbf). A variety of test modes are available including steady state, cyclic, and impulse bit testing. Test parameters, such as duration and test type, are entered via a personal computer and downloaded prior to testing to the digital data acquisition system. The data acquisition system both controls the test run operations and temporarily stores the research pressures, temperatures, loadcell measurements and calculated variables. At test completion the data are downloaded to the personal computer and stored on floppy disks. Testing has been conducted at oxygen-hydrogen mixture 
ratios of 3 to 8.5 and thrust levels up to $121 \mathrm{~N}$ (27.5 lbf). Performance and life testing have been completed on both component and complete rocket designs. A suite of diagnostics have been installed and are operational including a thrust stand, Rayleigh spectroscopy equipment, an infrared scanner, and a two-color pyrometer. Raman spectroscopy and laser-induced fluorescence diagnostics are being installed and checked out. This new test cell meets the need for a test facility with quick turn around and easy adaptability, thus providing high productivity with low staffing requirements to operate and maintain the facility.

\section{Acknowledgments}

This is to acknowledge the efforts of the many people involved in the construction and the day to day operations of the Rocket Laboratory - 11 test facility. Those people involved in the construction were from the NASA Engineering Design Division, the NASA Test Installations Division, the Analex Corporation and Sverdrup Technology, Inc. Those people, who continue to keep the cell functioning daily, are in the Test Installations Division. 


\section{References}

1 Korting, P.A.O.G. and H.J. Reitsma, "Theoretical and Experimental Evaluation of an Indoor Rocket Test Stand", Journal of Spacecraft and Rockets, Vol. 20 No. 3, May-June 1983, pp. 266-271.

2 Pirrello, C.J., R.D. Hardin, M.V. Heckart and K.R. Brown, "An Inventory of Aeronautical Ground Research Facilities", Vol III., NASA CR-1E76, November, 1971.

3 Scherrer, N. and A. Souchier, "Test Facilities for the Development of the HM60 LOX-LH2 Rocket Engine", IAF-84-309, 35 th congress of the International Astronautical Federation, october $7-13,1 \mathrm{~s} 8$.

4

Keller, T.A., "NASA Electric Rocket Test Facilities", Rocket Testing in Simulated space and High Altitude Environments, Vol 2, october, 1961.

5 Berton, Pierre, and Dominique Regard, "O.N.E.R.A. Ramjet Test Facilities", La Recherche Aerospatiale (English Edition), Aug.-Sept.1980, pp. 25-44.

6 Pearson, O.L., "Modification of a Very Large Test Chamber for Plasmasphere: Simulation", Journal of Spacecraft and Rockets, Vol. 17 No. 4, July-August 1980, pp. 323-326.

7 Schulz, R.J. and R.C.Bauer, "Rocket Plumes Testing in Ground Test Facjlties", AIAA Paper No. 72-1072, AIAA/SAE 8th Joint Propulsior Specialist Conference, November 29-December 1, 1972 .

8 Goethert, B.F., "High Altitude and space simulation Testing", Americ:an Rocket Society, No. 2060-61, October 9-15, 1961 .

9 Briley, G.L., and R.S. Iacabucci, "space station Hydorgen/Oxygen Thruster Technology", NASA Contract Report 182280, NAS3-251.42, Rockwell International Rocketdyne Division, Novemker 1988 .

10 Reed, B.D. and P.F. Penko, "Comparison of Experimental and Theoretical Performance of a 110 N Hydrogen/Oxygen Thruster", AIAA Paper 90-2(151, July 1990.

11 Seasholtz, F.G., S.J. Schneider, and F.J. Zupanc, "Spectrally Resolved Rayleigh Scattering Diagnostic for Hydrogen-oxygen Rocket Plume studies" to be published. 
12 Nickerson, G.R., D.E. Coats, A.L. Dang, S.S. Dunn, and H. Kehtarnavaz, "Two-Dimensional Kinetics(TDK) Nozzle Performance Computer Program", NAS8-36863, March 31, 1989.

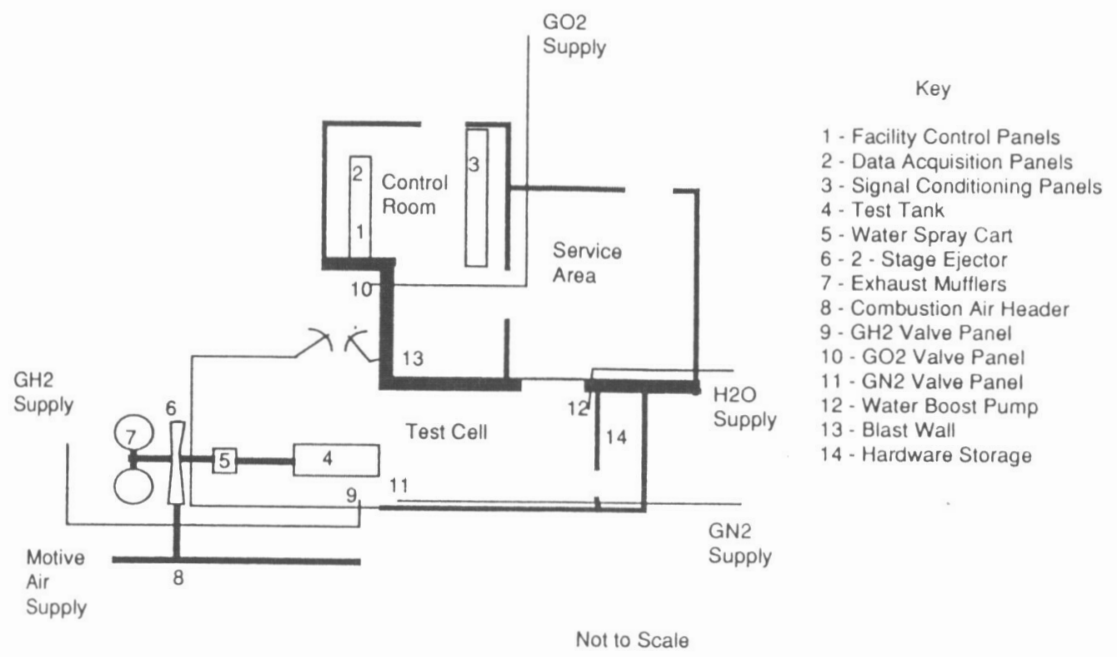

FIGURE 1. - LOW THRUST CHEMICAL ROCKET LABORATORY LAYOUT.

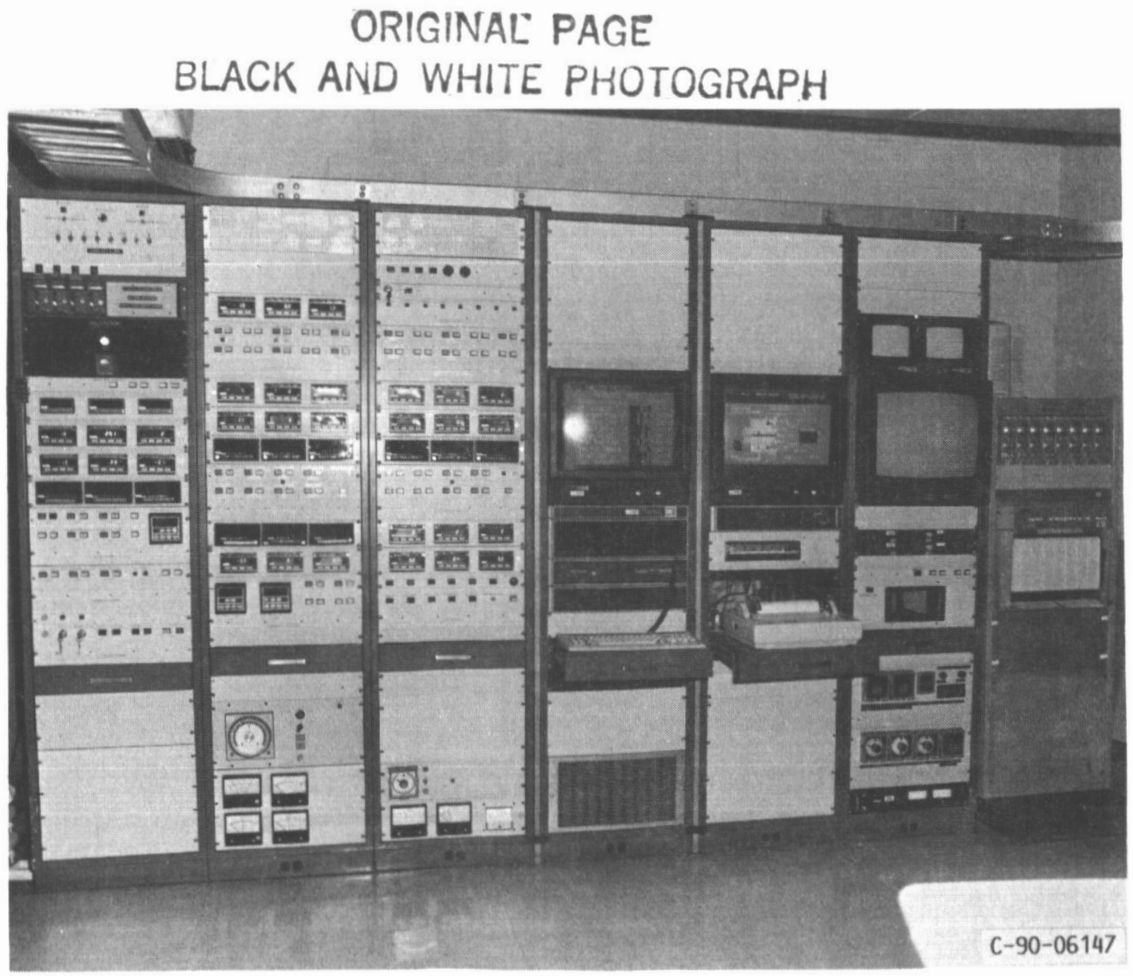

FIGURE 2. - CONTROL ROOM SHOWING FACILITY CONTROL PANELS AND DATA ACQUISITION EQUIPMENT. 


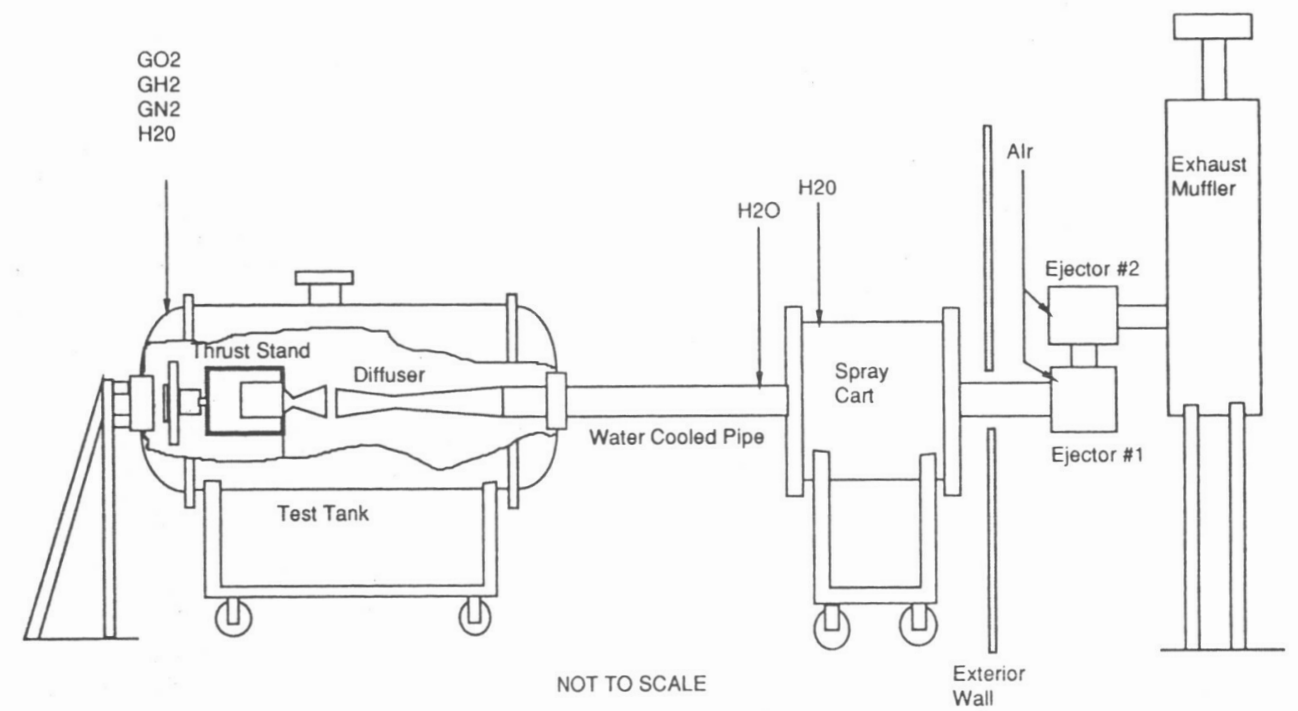

FIGURE 3. - LOW THRUST CHEMICAL ROCKET LABORATORY TEST RIG DIAGRAM.

\section{ORIGINAL PAGE \\ BLACK AND WHITE PHOTOGRAPH}

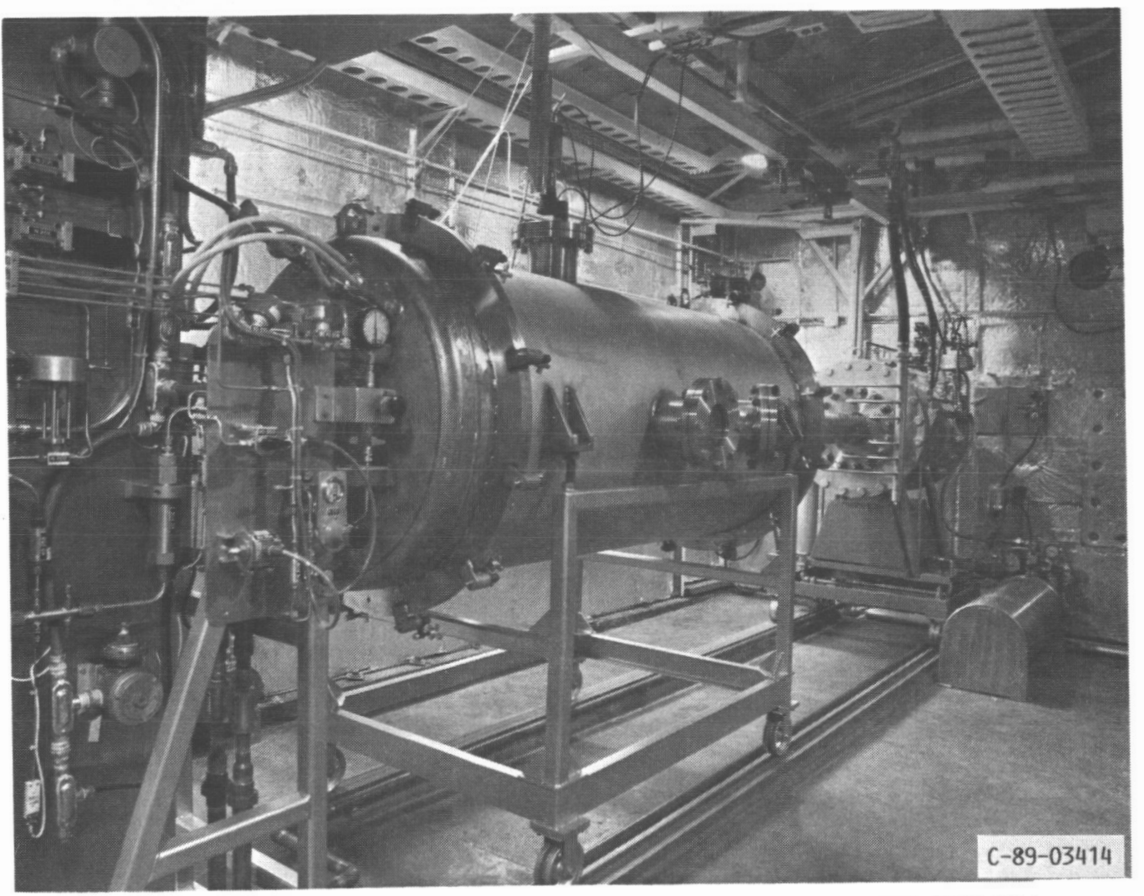

FIGURE 4. - TEST TANK, SPRAY CART, AND WATER REMOVAL SYSTEM IN THE TEST CELL. 


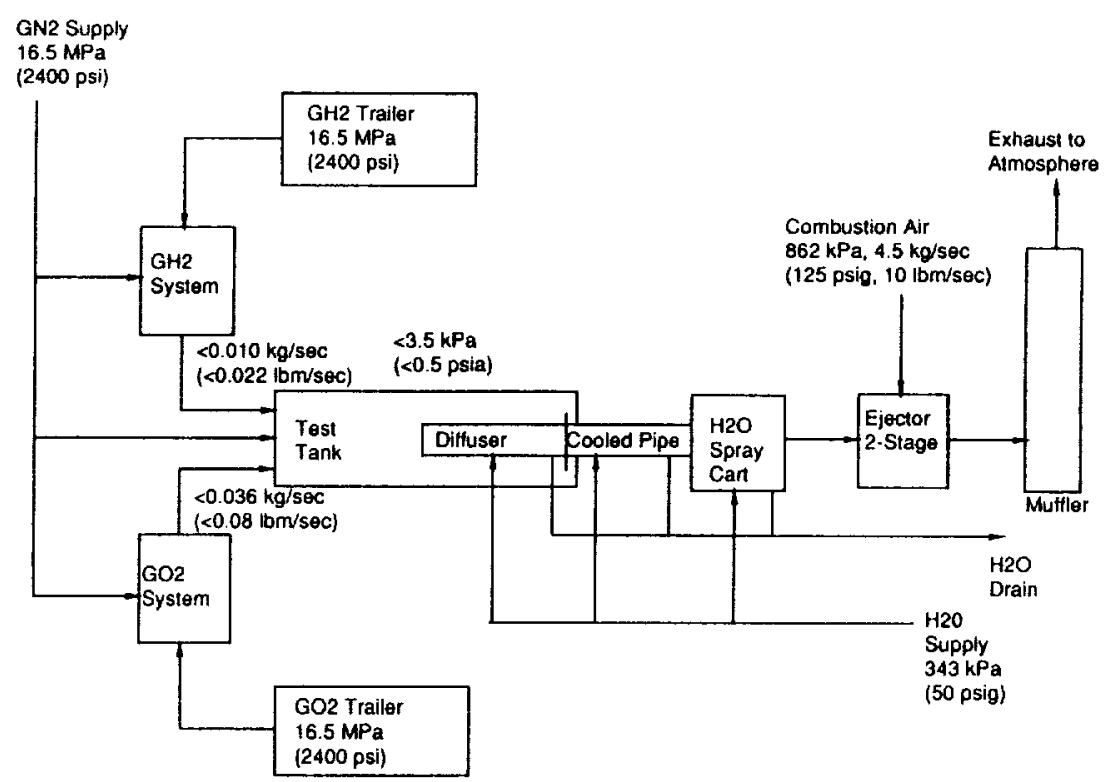

FIGURE 5. - BLOCK DIAGRAM OF MECHANICAL SYSIEMS INTERACTIONS.

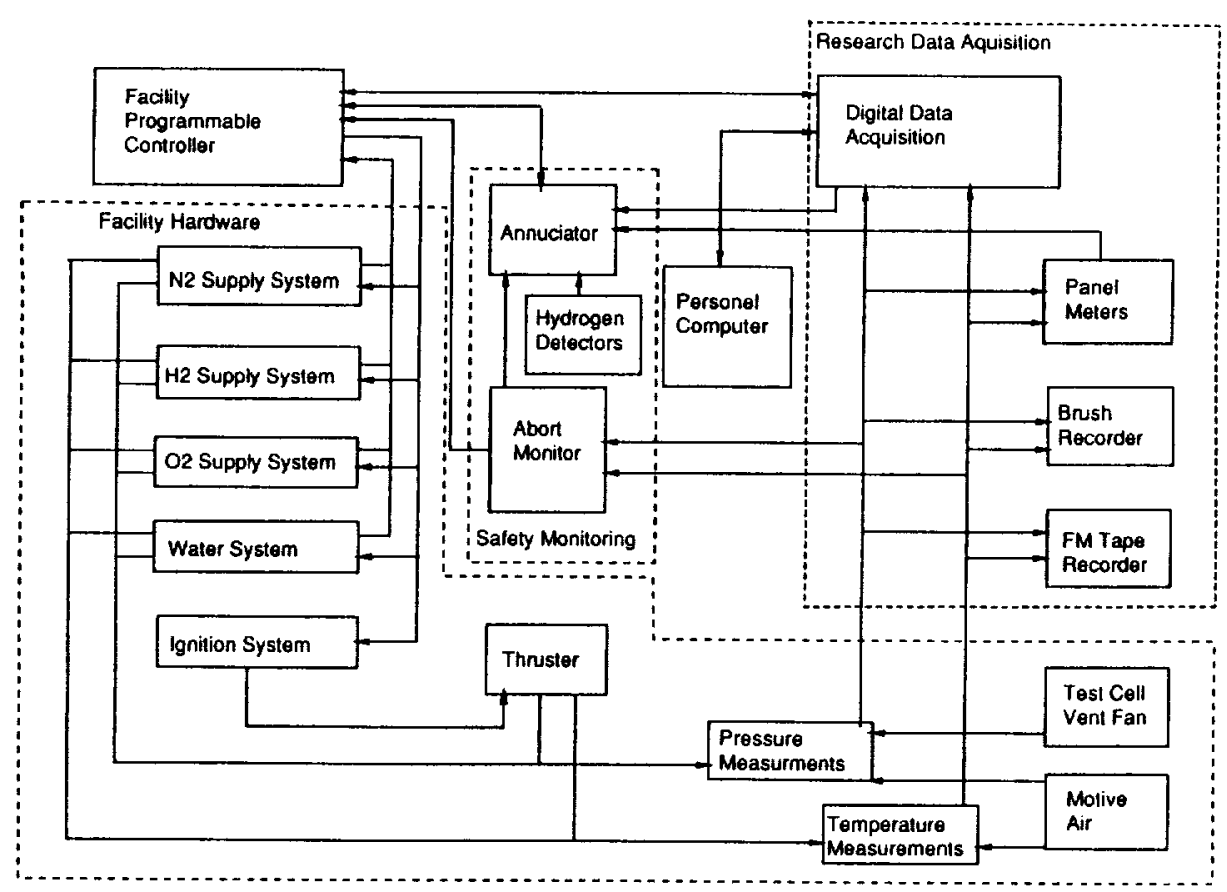

FIGLRE 6. - IMSTRUMENTAIION/CONTROL BLOCK DIAGRAM. 
ORIGINAL PAGE

BLACK AND WHITE PHOTOGRAPH

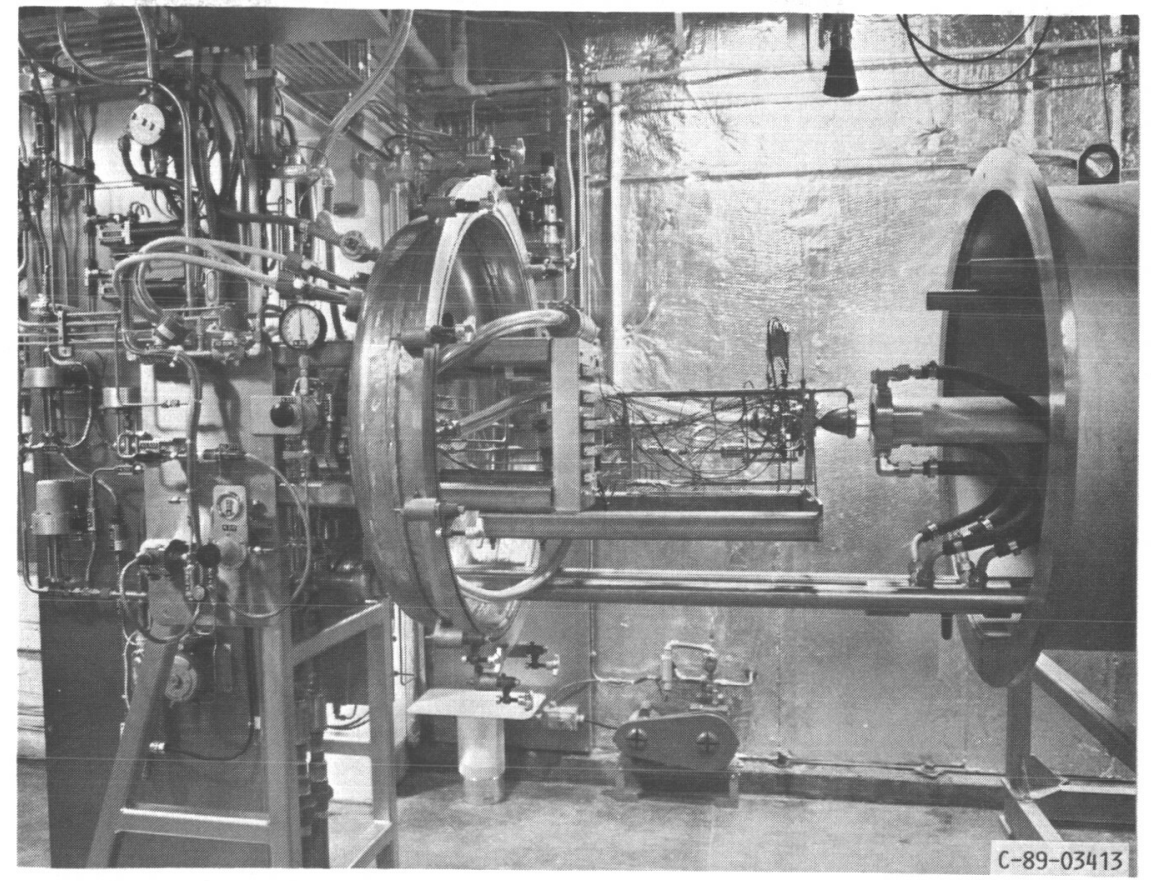

FIGURE 7. - TEST TANK ROLLED BACK FOR ACCESS TO THRUSTER AND THRUST STAND AT CENTER.

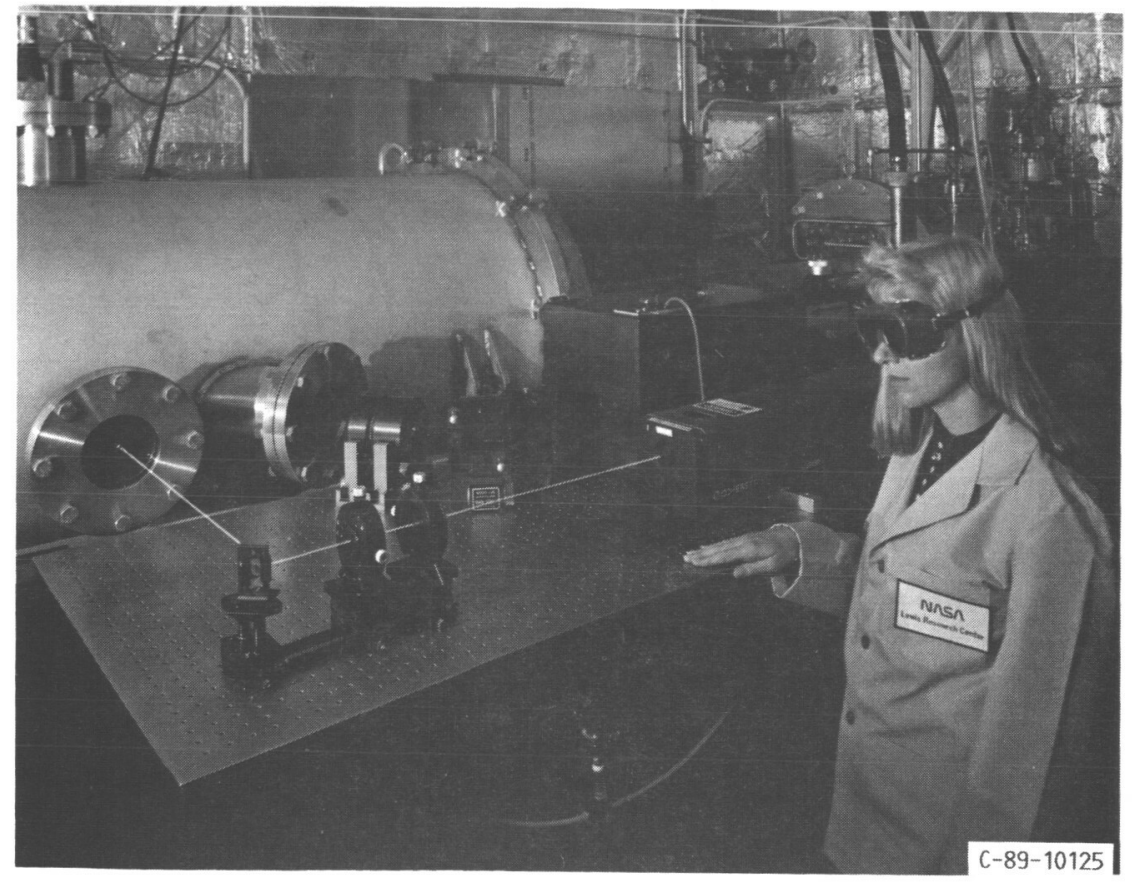

FIGURE 8. - RAMAN SPECTROSCOPY APPARATUS USING AN ARGON ION I ASER. 

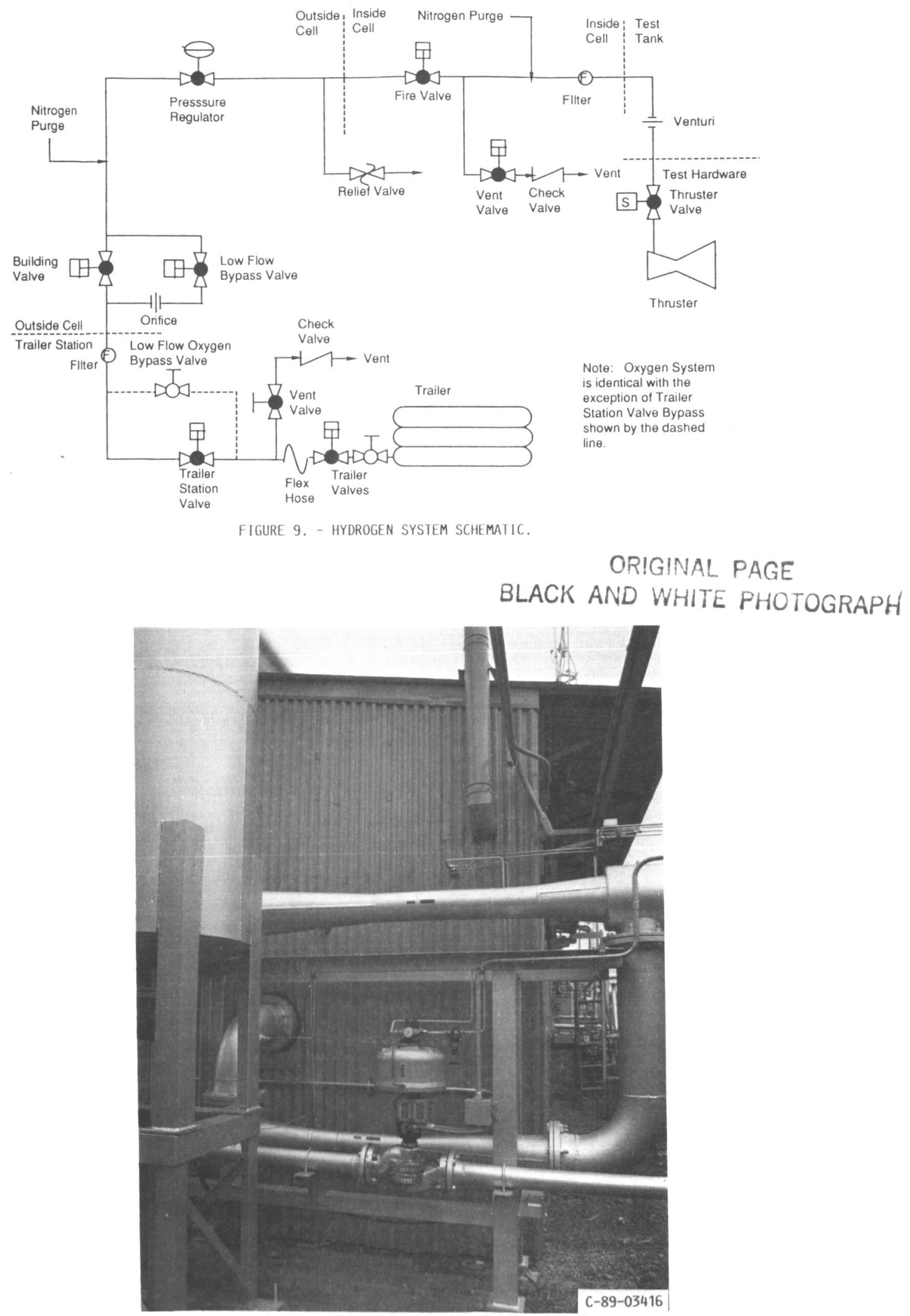

FIGURE 10. - TWO STAGE EJECTOR SYSTEM AND ONE EXHAUST MUfFLER. 


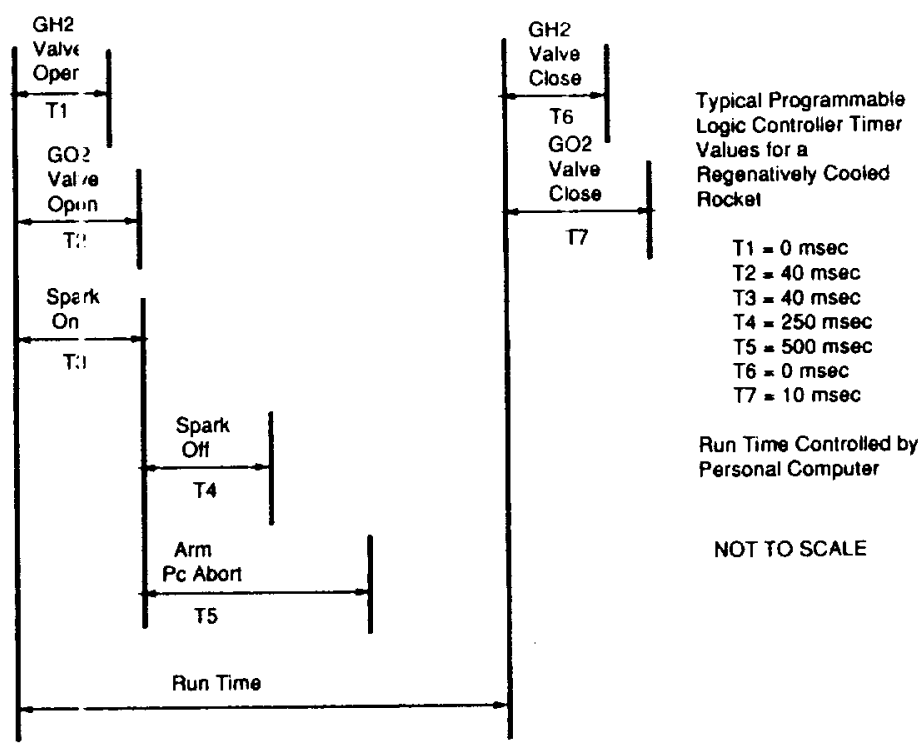

FIGURE 11. - TIMER SEQUENCE FOR LOW IHRUST CHEMICAL ROCKET IEST FACILITY.

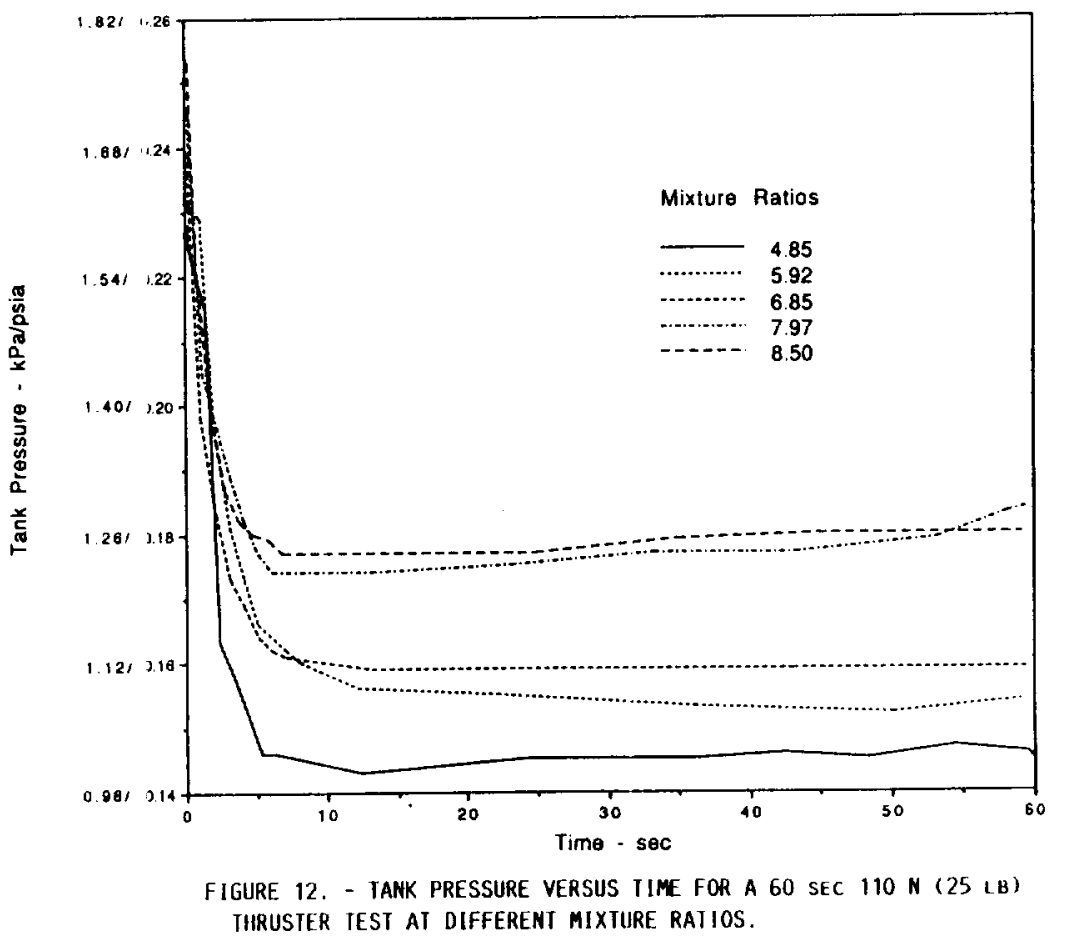




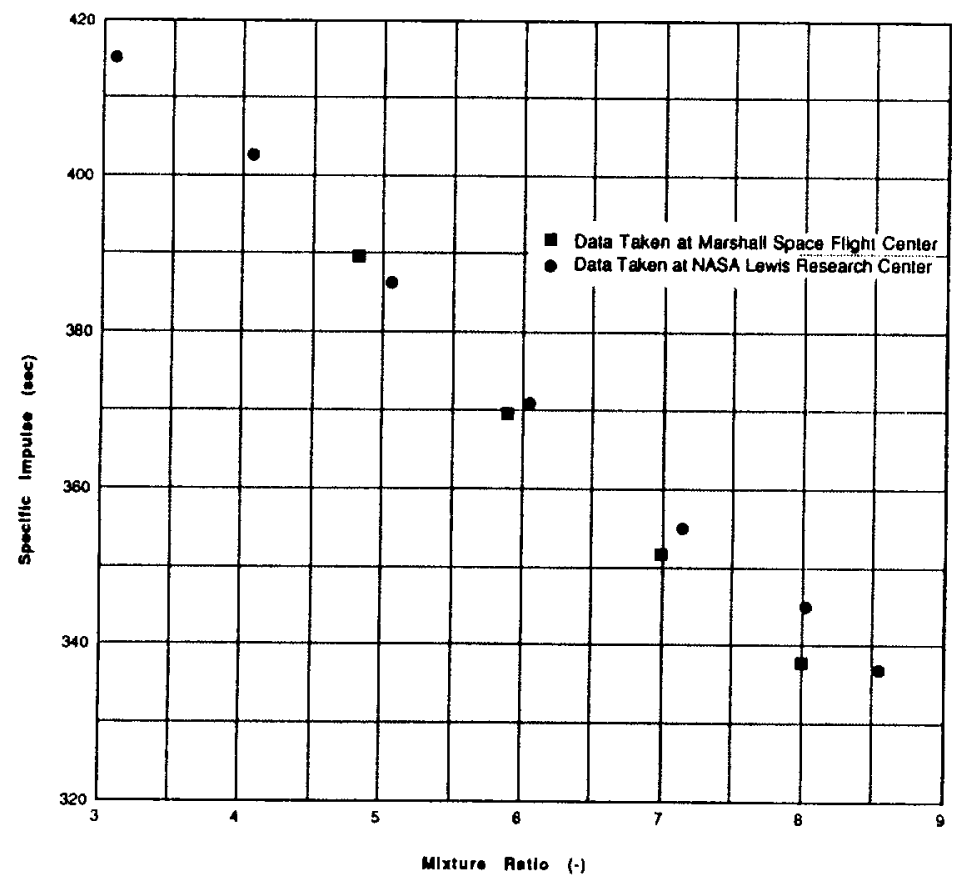

FIGURE 13. - SPECIFIC IMPULSE VERSUS MIXTURE RATIO FOR A $110 \mathrm{~N}$ (25 LB) THRUSTER FOR A CHAMBER PRESSURE $=690+/-34 \mathrm{kPA}(100+/-5 \mathrm{PSIA})$ AT DURATION OF $30 \mathrm{sEC}$. 


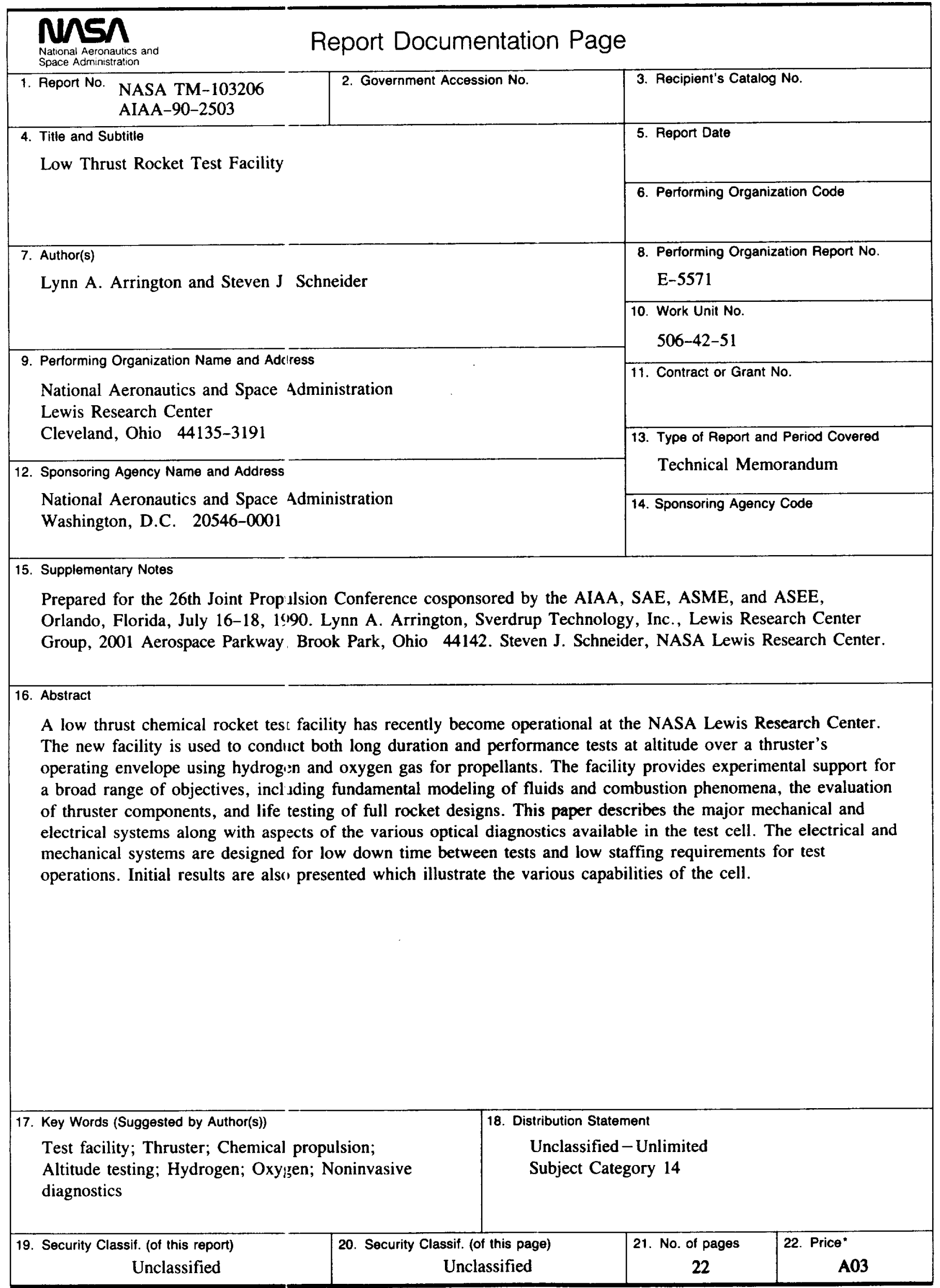


